\title{
Accommodative anomalies among schoolchildren in Abia State, Nigeria
}

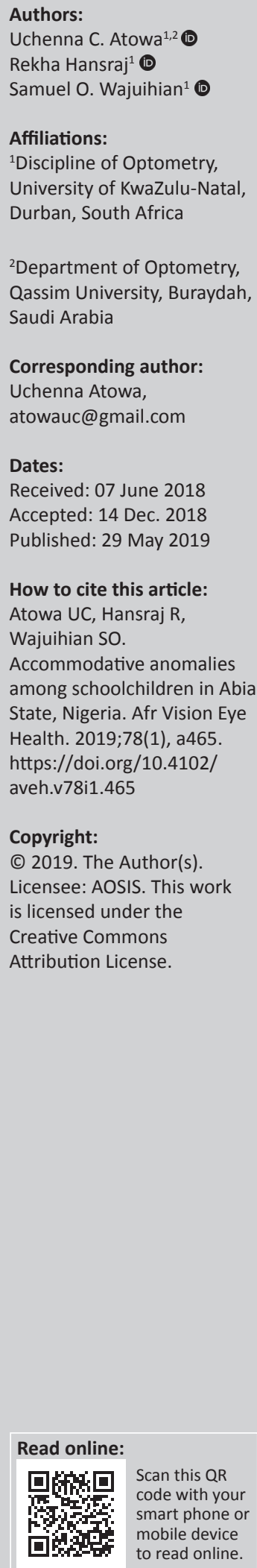

Background: Ocular discomfort resulting from accommodative anomalies can impair reading efficiency, school performance and possibly a person's quality of life.

Aim: The aim of this study is to determine the prevalence of accommodative anomalies in schoolchildren in Abia State, Nigeria, and to assess possible associations with sample demographics such as age, gender and school level.

Setting: The study was conducted in primary and secondary schools in Abia State, Nigeria.

Methods: Case history questionnaires and vision tests were administered to 537 (mean age $13.0 \pm 2.0$ years) children randomly selected from nine schools in Abia State. The following vision parameters were measured: visual acuity, non-cycloplegic refraction, cover test, near point of convergence, fusional vergences, accommodative functions and ocular health evaluation. All accommodative and binocular function tests were performed following the subjective refraction with compensating lenses in place, if prescribed. Anomalies of interest such as accommodative insufficiency, accommodative excess and accommodative infacility were classified using the findings of accommodative and vergence parameters.

Results: A total of $90(16.8 \%)$ children had accommodative anomalies. Prevalence estimates include accommodative insufficiency (3.9\%), accommodative excess (2.8\%) and accommodative infacility (10.1\%). There was no significant difference in the distribution of various accommodative anomalies between age group, gender or school level.

Conclusion: The significant proportion $(16.8 \%)$ of children with accommodative anomalies in the present study is an important finding, considering that paediatric vision screening programmes that only focus on visual acuity are unlikely to detect these critical visual anomalies. The result of this study is expected to direct the development of a common and broad vision screening strategy.

Keywords: accommodative anomalies; accommodative insufficiency; accommodative excess; accommodative infacility; children.

\section{Introduction}

Accommodative anomalies are visual conditions that can affect the eye's ability to alter its dioptric power to bring an object of regard coincident with the retina. ${ }^{1,2}$ Clinical signs range from reduced accommodative amplitude (AA), reduced sustainability and accuracy of accommodation and difficulty maintaining clear vision when changing fixation from one point to another with associated symptoms. ${ }^{1,2,3}$ The symptoms include blurred vision at near, transient blurred vision when looking at a distant target following performance of near work, headaches, pulling sensation around the eyes, tired eyes and reduced attention span. Because of these symptoms, individuals find themselves attempting to compensate by holding reading material too close or too far away, or simply avoiding near activities altogether. ${ }^{1,2,4,5,6}$ These ocular discomforts can impair reading efficiency, school performance and possibly a person's quality of life. ${ }^{7,9}$,

A number of studies $3,6,9,10,11,12,13,14,15,16,17,18,19,20$ have reported on the prevalence of accommodative anomalies in school-age children in different populations, especially in Caucasian children. For the specific populations indicated in Table 1, the prevalence range for different accommodative anomalies include accommodative insufficiency (AIS, $0.2 \%-18.3 \%$ ), accommodative excess (AE, $1.2 \%-5.1 \%$ ) and accommodative infacility (AIF, 2.5\% - 30\%). Differences in study designs including the use of single or multiple sign criteria in the definition of specific accommodative anomalies and methodological differences such as small sample sizes, convenience sampling method and exclusion criteria within studies may account for the variability in study findings. Regarding exclusion criteria, the most recurring flaws among the studies are the exclusion of 
TABLE 1: A summary of studies reporting the prevalence (\%) of accommodative anomalies in school-age children.

\begin{tabular}{|c|c|c|c|c|c|c|}
\hline \multirow[t]{2}{*}{ Authors } & \multirow[t]{2}{*}{ Setting } & \multirow[t]{2}{*}{ Age (years) } & \multirow[t]{2}{*}{ Sample size } & \multicolumn{3}{|c|}{ Prevalence $(\%)$} \\
\hline & & & & $\begin{array}{l}\text { Accommodative } \\
\text { insufficiency }\end{array}$ & Accommodative excess & $\begin{array}{l}\text { Accommodative } \\
\text { infacility }\end{array}$ \\
\hline Wajuihian and Hansraj ${ }^{6}$ & School & $13-19$ & 1201 & 4.5 & 2.8 & 12.9 \\
\hline Darko-Takyi et al. ${ }^{3}$ & School & $12-17$ & 627 & 7.7 & 1.4 & 3.8 \\
\hline \multirow[t]{2}{*}{ Hussaindeen $^{14}$} & School & $7-17$ & $358^{\dagger}$ & 0.2 & 0.8 & 7.0 \\
\hline & & & 562 & 0.0 & 0.0 & 10.7 \\
\hline Davis et al. ${ }^{12}$ & School & 11.7 (mean) & 484 & 32.4 & - & - \\
\hline Jang and Park ${ }^{13}$ & School & $8-13$ & 589 & 5.3 & 1.2 & 2.5 \\
\hline Shin et al. ${ }^{9}$ & School & $9-13$ & 114 & 18.3 & 3.9 & 13.4 \\
\hline Marran et al..$^{10}$ & School & 11.5 (mean) & 299 & 8.0 & - & - \\
\hline Borsting et al. ${ }^{11}$ & School & 8-15 & 392 & 17.0 & - & - \\
\hline Metsing and Ferreira ${ }^{15}$ & School & $8-13$ & 112 & 10.0 & - & 12.3 \\
\hline Moodley ${ }^{16}$ & School & $6-13$ & 264 & 24.0 & - & 30.0 \\
\hline Abdi et al. ${ }^{20}$ & School & $6-16$ & 264 & 24.2 & - & - \\
\hline Scheiman et al. ${ }^{17}$ & Clinic & $6-18$ & 1650 & 2.3 & 1.2 & 2.3 \\
\hline Paniccia and Ayala ${ }^{18}$ & Clinic & $5-20$ & 593 & 39.0 & 5.1 & 7.0 \\
\hline
\end{tabular}

$\dagger$, rural population

$\ddagger$ urban population.

children with uncorrected refractive error (RE). For the studies that did not exclude children with uncorrected RE, it was not clear whether they wore their compensating lenses during testing. This is important, as RE significantly impact the aetiology and influences the measurement and treatment of accommodative anomalies. ${ }^{1,7,12}$

There is also a lack of information in the literature on the influence of age, gender and school level on the prevalence of accommodative anomalies. ${ }^{6}$ As early detection remains the best approach for the treatment of visual anomalies and considering the cost of systematic screening, ${ }^{18}$ an understanding of the association between accommodative anomalies and sample demographics will allow dedicating available resources and efforts to early detection, such as regular vision screening only on people at risk, thereby reducing the high short-term and long-term costs to the health system and to society. Presently, there are no intervention and management guidelines for accommodative and vergence anomalies in Abia State and Nigeria because the subspecialty of paediatric optometry is relatively new in the country. ${ }^{21}$ The clinical implication is that most eye care professionals rarely consider accommodative and vergence disorders as anomalies of interest when screening children for near vision anomalies.

Our study included an adequate and representative sample of primary and secondary schoolchildren in Abia State, Nigeria. Accommodative and binocular vision tests were performed with children wearing their compensating lenses, if prescribed. This ensured that uncorrected RE did not negatively impact on the clinical outcome measures. The present study aimed to determine the prevalence of accommodative anomalies in Abia State schoolchildren and to assess possible association with age, gender and school level. The information is expected toguidehealth policymakers and practitioners in implementing the most appropriate intervention and management strategies, particularly for vision problems that have been associated with educational outcomes. ${ }^{8,9}$

\section{Methods Study participants}

This study is part of the broader survey that utilised crosssectional design to quantify visual conditions in schoolchildren in Abia State. The sampling design and technique have been reported elsewhere. ${ }^{22}$ In brief, the prevalence estimation formula was used to calculate an adequate sample size for a projected prevalence of $12.7 \%$ and adjustments were made for clustering effects (2.0) and nonparticipation (10\%). A total of 550 schoolchildren with ages ranging from 10 to 16 years were recruited from nine schools (public and private) through a stratified multistage and random sampling starting from the three geographic districts to the classrooms. Children who had systemic diseases or were taking any systemic and/or ocular medications that may affect near vision were excluded from the study. ${ }^{22}$

\section{Procedures}

Prior to the start of the vision test, a case history questionnaire covering areas such as the ocular and general health conditions of the participants, including near task characteristics and visual symptoms, was administered to the participants. The interview was conducted by a research assistant properly trained in the administration of the questionnaire. A series of vision tests that included visual acuity (VA) measurements, ocular motility evaluation, stereopsis, suppression test, non-cycloplegic autorefraction, subjective refraction, colour vision assessment, ocular health evaluation, accommodative and binocular vision test were performed by an optometrist (the principal investigator). All testings were conducted in test stations set up in classrooms provided by the school authorities, and test conditions including illumination and test distance were maintained as best as possible at the same level in each station.

Distance and near VA were measured for each eye with $\log$ MAR charts held at $3 \mathrm{~m}$ and $40 \mathrm{~cm}$, respectively, and all 
TABLE 2: Classification of accommodative anomalies.

\begin{tabular}{|c|c|c|}
\hline Accommodative anomalies & Clinical signs & Diagnostic criteria \\
\hline Accommodative insufficiency & $\begin{array}{l}\text { - Reduced AA of at least } 2.00 \mathrm{D} \text { below Hofstetter's calculation for minimum } \\
\text { amplitude: } 15-0.25 \times \text { age (years) } \\
\text { - High MEM }>+0.75 \mathrm{D} \\
\text { - Fails MAF testing with }-2.00 \mathrm{D} \text { with a criterion }<6 \mathrm{cpm}\end{array}$ & $\begin{array}{l}\text { A minimum of clinical signs ( } 1 \text { and } 2 \text { or } 1 \text { and } 3 \text {, or all } \\
\text { clinical signs) }\end{array}$ \\
\hline Accommodative excess & $\begin{array}{l}\text { - Low MEM }<+0.25 \mathrm{D} \\
\text { - Difficulty clearing }+2.00 \mathrm{D} \text { with MAF with a criterion }<6 \mathrm{cpm} \\
\text { - Fails BAF test with }+2.00 \mathrm{D} \text { with a criterion }<3 \mathrm{cpm}\end{array}$ & Clinical signs ( 1 and 2 or 1 and 3 ) \\
\hline Accommodative infacility & $\begin{array}{l}\text { - Normal AA } \\
\text { - Fails MAF using } \pm 2.00 \mathrm{D} \text { lenses, with a criterion of } \mathrm{MAF}<11 \mathrm{cpm} \\
\text { - Fails BAF using } \pm 2.00 \mathrm{D} \text { lenses, with a criterion of } \mathrm{BAF}<8 \mathrm{cpm}\end{array}$ & All clinical signs \\
\hline
\end{tabular}

D, dioptre; MEM, monocular estimation method; MAF, monocular accommodative facility; cpm, cycles per minute; BAF, binocular accommodative facility; AA, amplitude accommodative.

children underwent non-cycloplegic autorefraction and subjective refraction irrespective of their VA. We did not apply cycloplegia as this would have complicated the evaluation of near vision functions, which were the focus of the present study. Alternatively, the plus lens (2 D) test was performed on all children to detect possible latent hyperopia.

Accommodative and binocular function tests were performed in three repeated measures after subjective refraction with the child wearing his or her near correction, if prescribed. Monocular and binocular AA were determined by using Donders' push-up to blur technique with the Royal Air Force (RAF) rule. The target was a single line of letters equivalent to a VA of $6 / 9$ on a reduced target, and the point of first sustained blur was recorded in dioptres (D). Accommodative facility was measured monocularly (MAF) and binocularly (BAF) with a plus or minus $2 \mathrm{D}$ lens flipper at $40 \mathrm{~cm}$. The target was a single line of letters that corresponded to a near $\mathrm{VA}$ of 6/9. Accommodative response was measured objectively at $40 \mathrm{~cm}$ using the monocular estimation method retinoscopy. For the vergence, parameters including horizontal phoria, AC/A ratio, near fusional vergence ranges and near point of convergence, the description of the test protocols and techniques have been provided in the report on vergence anomalies. ${ }^{22}$

\section{Classification of the outcome variables}

Accommodative anomalies were diagnosed as AIS, AE and AIF using the clinical measures of accommodative variables, according to the criteria used by previous studies,,$^{2,6,9,13,14}$ as shown in Table 2.

\section{Statistical analysis}

The data analysis was performed using SPSS for Windows, version 23.0 (IBM-SPSS, Chicago, IL, United States). Descriptive analysis of accommodative findings were presented as means, standard deviations, medians, ranges (minima and maxima), as well as skewness and kurtosis, while frequencies and distributions of outcome measures were presented in tables and figures. Differences in proportions among groups were examined using Pearson's chi-squared tests, whereas differences in the group means between children with and without accommodative anomalies were explored using the two-sample $t$-tests. Differences were considered significant at $p$-values of less than or equal to 0.05 .

\section{Ethical considerations}

Ethical approval for the study protocol was granted by the College of Medicine Health Research and Ethics Committee, University of Nigeria, Enugu Campus (ethical clearance number: 023/01/2017), as well as the Biomedical Research Ethics Committee of the University of KwaZulu-Natal, Durban, South Africa (ethical clearance number: BE/619/16). The school heads or principals also approved the study. Written informed consent and assent were obtained from parents and children, respectively, after verbal and written explanation of the nature of the study was provided to them. The study was conducted in accordance with the tenets of the Declaration of Helsinki regarding research involving humans.

\section{Results}

\section{Sample demographics}

Five hundred and thirty-seven children were examined, and four who had strabismus or amblyopia were excluded. Data were analysed for 533 children, and their mean age was $13.0 \pm$ 2.0 years. The participants comprised $223(41.9 \%)$ children with ages ranging from 10 to 12 years (age group 1) and 310 (58.1\%) with ages ranging from 13 to 16 years (age group 2); 279 (52.4\%) were female and $254(47.6 \%)$ male; $233(43.8 \%)$ were in primary and $300(56.2 \%)$ in secondary school. The prevalence of REs in the study sample was hyperopia (4.1\%), myopia (3.4\%) and astigmatism (3.2\%). All participants had near VA of at least $\mathrm{N}_{5}$ with mean best-corrected distance VA ( $\log$ MAR) of the right eye as $-0.09 \pm 0.04$ and left eye as -0.09 \pm 0.03 . The descriptive statistics for accommodative variables are represented in Table 3.

\section{Prevalence of accommodative anomalies}

The prevalence of accommodative anomalies was computed using both single and multiple sign criteria. The prevalence estimation (for multiple sign criteria) was for accommodative anomalies that were not associated with vergence disorders. With the multiple sign criteria, a total of $90(16.8 \%)$ children had accommodative anomalies. The prevalence of the specific types of accommodative anomalies is presented in Table 4. For the single sign criterion, based on some specific clinical measures listed in Table 2, reduced monocular AA was observed in $44(7.8 \%)$ participants, while reduced binocular AA was recorded for 39 (7.3\%) children.

A plot of the mean monocular AA as a function of age is presented in Figure 1. The figure shows that AA decreased 
TABLE 3: Descriptive analysis of overall accommodative findings of schoolchildren in Abia State

\begin{tabular}{|c|c|c|c|c|c|c|c|c|}
\hline Variables & $n$ & Mean & SD & Median & Minimum & Maximum & Skewness & Kurtosis \\
\hline \multicolumn{9}{|c|}{ Amplitude of accommodation (D) } \\
\hline Monocular (RE) & 533 & 15.25 & 3.58 & 16.0 & 4.0 & 20.0 & -0.92 & -0.39 \\
\hline Binocular (RE) & 533 & 15.46 & 3.44 & 16.0 & 5.0 & 20.0 & -1.48 & 0.92 \\
\hline $\begin{array}{l}\text { Accommodative } \\
\text { response (D) }\end{array}$ & 533 & 0.47 & 0.27 & 0.5 & -0.5 & 1.5 & 0.73 & 4.94 \\
\hline \multicolumn{9}{|c|}{ Accommodative facility (cpm) } \\
\hline$-2 \mathrm{D}$ monocular & 527 & 11.36 & 3.35 & 11.0 & 1.0 & 20.0 & -0.11 & -0.28 \\
\hline$-2 \mathrm{D}$ binocular & 529 & 11.38 & 3.39 & 11.0 & 1.0 & 20.0 & -0.12 & -0.37 \\
\hline +2 D monocular & 528 & 11.45 & 3.94 & 11.7 & 0.0 & 20.0 & -0.15 & -0.67 \\
\hline$+2 \mathrm{D}$ binocular & 528 & 11.85 & 4.15 & 12.0 & 2.0 & 21.0 & -0.10 & -0.59 \\
\hline $\pm 2 \mathrm{D}$ monocular & 527 & 9.04 & 3.17 & 9.0 & 1.7 & 18.0 & -0.20 & 0.90 \\
\hline $\pm 2 \mathrm{D}$ binocular & 527 & 9.27 & 2.98 & 9.3 & 2.0 & 18.0 & -0.05 & 0.57 \\
\hline
\end{tabular}

$\mathrm{D}$, dioptre; RE, right eye; cpm, cycles per minute; $n$, number; SD, standard deviation.

TABLE 4: Prevalence of accommodative anomalies among Abia State schoolchildren.

\begin{tabular}{lcc}
\hline Accommodative anomaly & $\begin{array}{c}\text { Number of children } \\
(\boldsymbol{n})\end{array}$ & $\begin{array}{c}\text { Prevalence } \\
(\mathbf{\%})\end{array}$ \\
\hline Accommodative insufficiency & 21 & 3.9 \\
Accommodative excess & 15 & 2.8 \\
Accommodative infacility & 54 & 10.1 \\
\hline
\end{tabular}

with age; however, the decrease was not particularly linear. A minimal increase in mean AA was observed from ages 11 to 12 years, while the mean AA was 15.7 at age 13 years and 15.8 at 14 years. Accommodative facility was tested with a plus and minus $2 \mathrm{D}$ lens flipper, and the result showed that $96(18.3 \%)$ children failed MAF (right eye), while $235(44.6 \%)$ failed BAF. For accommodative response, $28(5.2 \%)$ children had accommodative lead, whereas 17 (3.1\%) had accommodative lag.

Regarding the effect of age, gender and school level on the prevalence of the AIS, AE and AIF, statistical analysis (Figure 2) showed that despite the marginal differences observed between the groups, none of the accommodative anomalies were associated with age, gender or school level.

\section{Comparison of accommodative findings and groups}

The group mean data for specific accommodative parameters for children with no accommodative anomaly and children with various accommodative anomalies were compared using the two sample $t$-test (Table 5). Analysis of the mean data of the clinical measures for AIS group revealed that except for accommodative accuracy, which showed a significant increase $(p<0.001)$, all other accommodative parameters were significantly reduced when compared to the no accommodative anomaly group $(p<0.001)$ for all other variables. For $\mathrm{AE}$, the group mean data for accommodative response $(p<0.001)$ and $+2.00 \mathrm{D}$ accommodative facility (monocular, $p<0.001$; binocular, $p<0.001$ ) were significantly reduced. Similarly, both monocular and binocular $( \pm 2.00 \mathrm{D})$ accommodative facility variables were significantly reduced (monocular, $p<0.001$; binocular, $p<0.001$ ) in children with AIF anomalies. However, no significant difference was observed for either monocular ( $p=0.08)$ or binocular $(p=0.44)$ AA between children with AIF and those without accommodative anomalies.

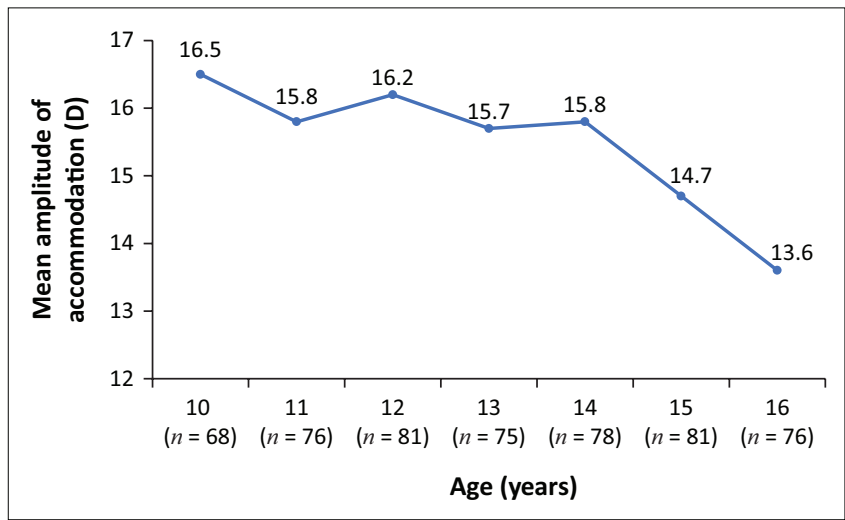

FIGURE 1: Mean monocular amplitude of accommodation as a function of age of schoolchildren $(N=533)$ in Abia State.

\section{Discussion}

This study reports on the prevalence of accommodative anomalies in a population of children of Abia State, which include AIS (3.9\%), AE (2.8\%) and AIF (10.1\%). There was no significant difference in the distribution of the various accommodative anomalies between age group, gender or school level. The mean AA of $15.46 \pm 3.44 \mathrm{D}$ in our study was comparatively similar to the $15.88 \pm 3.46 \mathrm{D}$ reported by Ovenseri-Ogbomo and Oduntan ${ }^{23}$ on school-age children in Nigeria.

In the present study, the prevalence of AIS (3.9\%) using multiple sign criteria was higher than the $2.3 \%$ reported by Scheiman et al. ${ }^{17}$ and $0.2 \%$ by Hussaindeen et al. ${ }^{14}$ However, the value is lower than two other studies ${ }^{6,9}$ that also utilised more than one clinical sign. The study by Shin et al. ${ }^{9}$ estimated AIS in symptomatic participants with a score of 20 or more on the convergence insufficiency symptom survey; hence, the reported prevalence of $18.3 \%$ may have been overestimated, while the difference of $4.5 \%$ reported by Wajuihian and Hansraj ${ }^{6}$ may be attributed to reduction in AA with an increase in age, as their study participants were older than the children in the present study. Further, studies that defined AIS using only one clinical sign (of reduced AA, lower than the expected age norm according to Hofstetter's formula for minimum age) reported significantly higher prevalence rates, ranging between $10 \%$ and $24.2 \% .^{15,16,19,20}$ However, to accurately interpret the accommodative status 


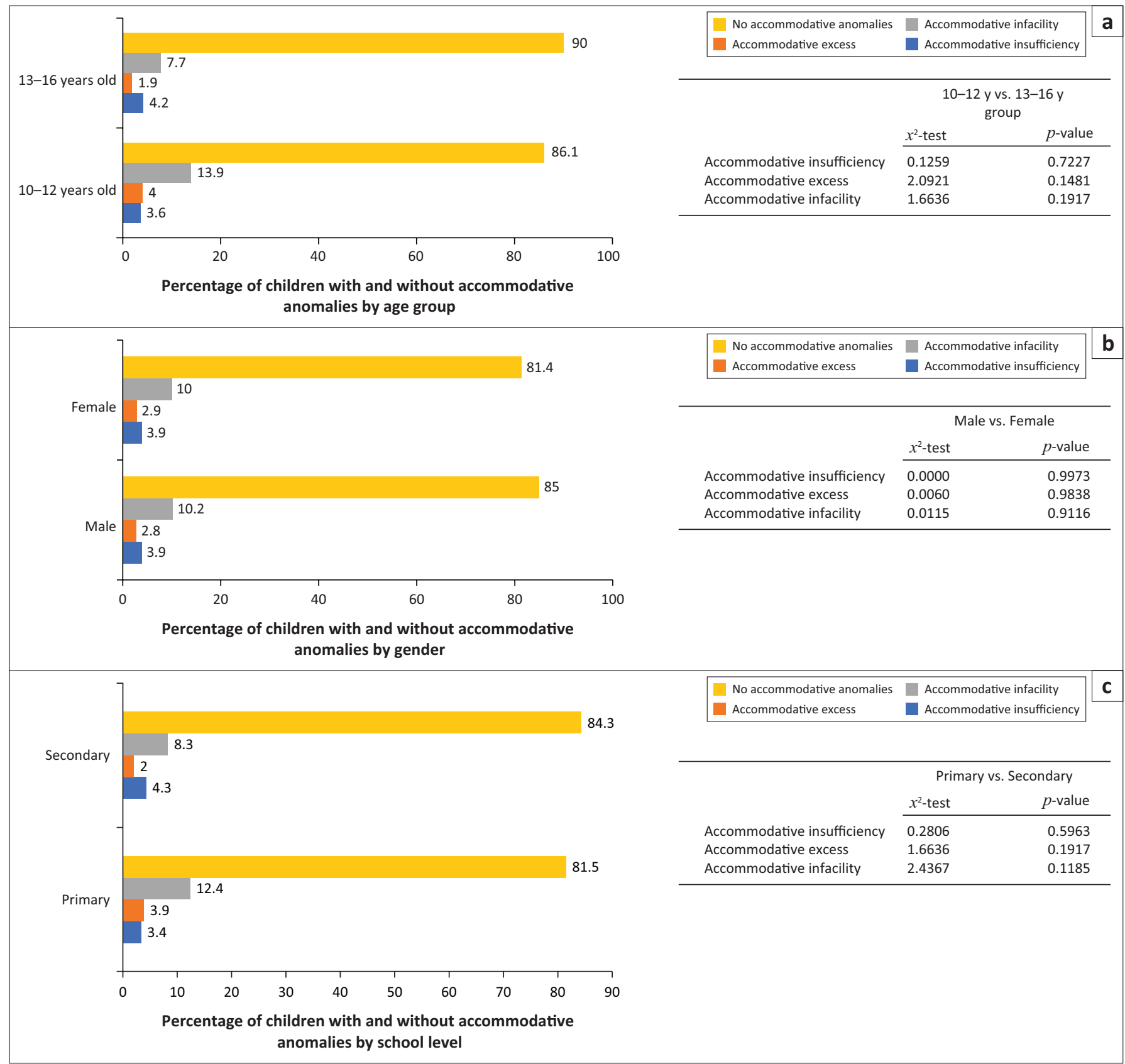

FIGURE 2: Distribution of specific accommodative anomalies by (a) age group, (b) gender and (c) school level.

TABLE 5: Accommodative findings for various accommodative groups.

\begin{tabular}{|c|c|c|c|c|c|c|c|c|c|c|c|c|}
\hline \multirow[t]{2}{*}{ Variable } & \multicolumn{3}{|c|}{$\begin{array}{l}\text { No accommodative anomalies } \\
\qquad(n=443)\end{array}$} & \multicolumn{3}{|c|}{$\begin{array}{l}\text { Accommodative insufficiency } \\
\qquad(n=21)\end{array}$} & \multicolumn{3}{|c|}{$\begin{array}{c}\text { Accommodative excess } \\
(n=15)\end{array}$} & \multicolumn{3}{|c|}{$\begin{array}{l}\text { Accommodative infacility } \\
(n=54)\end{array}$} \\
\hline & Mean & SD & Median & Mean & SD & Median & Mean & SD & Median & Mean & SD & Median \\
\hline \multicolumn{13}{|l|}{ Accommodative amplitude (D) } \\
\hline Monocular (RE) & 17.51 & 4.04 & 18.00 & 7.18 & 1.31 & 6.00 & 19.26 & 2.08 & 18.00 & 17.30 & 3.72 & 20.00 \\
\hline Binocular & 17.59 & 3.62 & 20.00 & 7.32 & 1.28 & 7.30 & 19.30 & 2.04 & 20.00 & 17.66 & 3.29 & 20.00 \\
\hline Accommodative response (D) & 0.45 & 0.23 & 0.50 & 0.89 & 0.16 & 0.83 & -0.20 & 0.16 & 0.00 & 0.56 & 0.35 & 0.50 \\
\hline \multicolumn{13}{|l|}{ Accommodative facility (cpm) } \\
\hline$-2 \mathrm{D}$ monocular & 12.20 & 3.21 & 12.00 & 4.40 & 0.97 & 5.00 & 8.84 & 0.95 & 9.00 & 8.10 & 3.36 & 8.00 \\
\hline$-2 \mathrm{D}$ binocular & 12.26 & 3.27 & 12.00 & 4.67 & 0.90 & 4.30 & 8.79 & 1.14 & 8.30 & 8.18 & 3.38 & 8.00 \\
\hline +2 D monocular & 12.34 & 3.53 & 13.00 & 8.77 & 2.83 & 10.00 & 3.87 & 0.65 & 4.00 & 6.95 & 2.95 & 6.00 \\
\hline +2 D binocular & 12.79 & 3.58 & 13.00 & 8.77 & 2.85 & 9.30 & 3.64 & 0.94 & 4.00 & 7.30 & 3.43 & 7.00 \\
\hline \pm 2 D monocular & 10.09 & 2.42 & 10.00 & 4.71 & 1.09 & 5.00 & 3.48 & 0.91 & 4.00 & 3.99 & 1.91 & 4.50 \\
\hline $\pm 2 \mathrm{D}$ binocular & 10.30 & 2.21 & 10.00 & 4.83 & 1.06 & 5.00 & 3.47 & 0.87 & 4.00 & 4.66 & 1.61 & 5.00 \\
\hline
\end{tabular}

D, dioptres; RE, right eye; cpm, cycle per minute; SD, standard deviation. 
of children, it is recommended to include the assessment of other accommodative parameters such as accommodative facility and response. This is so because using only reduced AA overestimates the prevalence of AIS, ${ }^{1,2}$ because AIS presents more as a syndrome. Moreover, the prevalence of poor monocular $(7.8 \%)$ and binocular $(7.3 \%)$ AA reported in this study was lower than the $10 \%$ (monocular or binocular) reported by Metsing and Ferreira ${ }^{15}$ and the $24 \%$ (monocular) and $26 \%$ (binocular) reported by Moodley ${ }^{16}$ on primary schoolchildren but higher than the $4.6 \%$ (monocular) found by Wajuihian and Hansraj ${ }^{6}$ in high school children. Although several factors such as sampling methods and sample sizes, inconsistent measuring techniques and diagnostic criteria can play a significant role in differences between studies, the major reason here may be interexaminer variability and age of study participants. Younger children may have more difficulty in reporting blur than older children, which is the subjective criterion for the measurement of AA.

The findings of this study on AE (2.8\%) were consistent with those of Wajuihian and Hansraj ${ }^{6}$ on black students in South Africa. However, it should be noted that two other schoolbased studies in South Korea ${ }^{9,13}$ and another in Ghana ${ }^{3}$ reported different estimates of $1.2 \%,{ }^{13} 1.4 \%{ }^{3}$ and $3.7 \%,{ }^{9}$ respectively. Similarly, Darko-Takyi et al. ${ }^{3}$ and Jang and Park ${ }^{13}$ reported prevalences of AIF of $3.8 \%$ and $2.5 \%$, respectively, which is lower than our finding of $10.1 \%$. Other studies reported higher estimates when compared to the present study. A case in point: in South Korea, ${ }^{9}$ the prevalence of AIF was $13.4 \%$ while in South Africa ${ }^{6}$ it was $12.9 \%$, and in rural and urban India ${ }^{14} 7 \%$ and $10.7 \%$ were determined, respectively.

Although marginal differences between groups were observed in the present study, no significant differences were found between the prevalence of AIS, AE, AIF and demographic factors including age, gender and school level, which corroborates the findings of several other studies. ${ }^{3,9,13,18}$ The study by Scheiman et al. ${ }^{17}$ that found a significant difference in the prevalence of AIS with age was a clinicbased study that was exposed to biased data, making comparison of findings with a randomised school-based study very difficult.

Overall, the differences in relation to findings of these studies can be explained from various contexts. Although most of the studies enumerated in Table 1 were school-based studies, their sample size and sampling method varied considerably. To obtain more accurate prevalence data, it is necessary to have adequate and representative samples of the target population, with a suitable age range that will provide reliable data that can be extrapolated to the entire population. Except for three studies ${ }^{3,6,13}$ that utilised randomised samples, all others selected their participants and only a few had an adequate sample size, with Scheiman et al. ${ }^{17}$ being a clinical study. Clinic samples and school-based studies with only symptomatic participants are characteristically biased and have the possibility of reporting higher prevalence estimates when compared to an unselected population of children. ${ }^{22,24}$
Besides being non-representative samples, participants with complaints of visual discomfort are more prone to having actual visual anomalies. 22,24

The refractive status of the participants is another important factor to consider in assessing prevalence of an accommodative anomaly. Studies have indicated that uncorrected RE can impact the aetiology and influence accommodative anomalies, as well as their treatment options. ${ }^{7,12}$ From this point of view, it may be possible to suggest that RE affects the prevalence and distribution of accommodative anomalies in any population..$^{25}$ Myopes have reduced sensitivity to blur compared to hyperopes and emmetropes. ${ }^{1}$ Blur adaptation can cause an individual to experience sustained blur at closer distances during push-up testing, resulting in higher values of AA. ${ }^{1,25}$ Therefore, adequate correction of RE is critical in the resolution of some accommodative conditions ${ }^{12,25,26}$ and is likely to yield more accurate prevalence estimates. ${ }^{12}$ To ensure that uncorrected RE does not overestimate the prevalence of accommodative anomalies in our study, children were tested with the correction; however, in some studies $^{9,10,11,19}$ information regarding the refractive status of the participants was not indicated. As such, it was not clear whether those with RE were included in the study or whether they were examined with their spectacle compensations in place. Other studies excluded participants with uncorrected VA and RE, thereby limiting the extent to which their samples can be a valid representative of the target population.

Increased variability and reduced reliability associated with accommodative testing could also be the reasons for the variations in findings among studies. Some studies applied a single criterion, while others used two or more criteria to define specific accommodative anomalies. In addition to varying diagnostic criteria, different techniques were applied in measuring the accommodative parameters. Even in studies with similar criteria and measuring techniques, different cut-off points were applied in the detection of participants with specific accommodative anomalies, making it difficult to compare results among studies. Regarding reliability of test results, the measurement of accommodative parameters involves reporting blur experience, which depends on the ability of the subjects to understand the experimental procedures and instructions. Younger children have difficulty in reporting blur experience. ${ }^{6,22,23}$ As such the use of only younger (primary school) children by some studies may have influenced their results. With the exception of Jang and Park, ${ }^{13}$ school-based studies (Table 1) with younger children reported higher prevalences of AIF compared to those with older children. The difference between the findings of Jang and Park and the present study and others may be related to differences in test procedures, varying diagnostic criteria and cut-off points.

One of the limitations of the present study was the non-use of cycloplegia during refraction. Cycloplegia was contradicted because the study involves the evaluation of accommodative status, and our desire was to examine the children in their habitual state. Instead the plus lens test was applied in the 
assessment of latent hyperopia. Another possible limitation is that all tests were performed in test stations set up in each school, rather than an optometry clinic, which would have afforded better control over the test environment. Nevertheless, testing conditions were standardised at each test station in all the schools. In addition, validated and reliable instruments were applied in data collection, with only one examiner conducting all the vision tests. The study included an adequate sample representative of primary and secondary school children representing the learning experience and visual characteristics of these two levels of educations. Furthermore, the study protocol was adapted from recent studies ${ }^{6,12,14}$ in this area. Altogether, data from the present study have significant indications for eye care practitioners with respect to clinical management of near vision disorders as well as education and health policymakers in terms of planning and implementation of school health programmes. Given the reported association between school performance and accommodative anomalies, $7,8,9$ the accommodative status of every child who presents with near vision related complaints, particularly those having difficulty with academic performance, should be properly evaluated for possible accommodative disorder.

\section{Conclusion}

The present study has provided a detailed and systematic report on the prevalence of accommodative anomalies in children in Abia State, Nigeria. Our data indicate that a considerable proportion $(16.8 \%)$ of schoolchildren suffer from at least one of the disorders of accommodative function, which can have a substantial influence on their learning capabilities and academic performance. This is an important finding, given that conventional vision screening programmes that only focus on VA assessment are unlikely to detect these critical visual anomalies. Therefore, the scope of paediatric vision screening programmes should be widened to include test batteries that will identify common visual anomalies, including accommodative anomalies capable of affecting school performance. Overall, the data from this study will apply towards the development of a common and broadbased vision screening strategy.

\section{Acknowledgements}

The authors greatly appreciate the invaluable contribution of Dr Chikezie Ekpoma during the data collection process.

\section{Competing interests}

The authors report no conflicts of interest that may have influenced the writing of this article.

\section{Authors' contributions}

The manuscript was written by U.C.A., with R.H. and S.O.W. providing feedback on the structure and content of the manuscript.

\section{References}

1. Duckman RH. Visual development, diagnosis and treatment of paediatric patient accommodation. 1st ed. Philadelphia, PA: Lippincott Williams \& Wilkins; 2006.

2. Scheiman M, Wick B. Clinical management of binocular vision. Heterophoric, accommodative, and eye movement disorders. Philadelphia, PA: Lippincott Williams \& Wilkins; 2008.

3. Darko-Takyi CD, Khan NE, Nirghin U. Symptomatic accommodative disorders and asthenopia: prevalence and association in Ghanaian children. Afr Vis Eye Health 2016;75:a343. https://doi.org/10.4102/aveh.v75i1.343

4. Dwyer P. Clinical criteria for vergence accommodation dysfunction. Clin Exp Optom. 1991;74:112-119. https://doi.org/10.1111/j.1444-0938.1991.tb04622.x

5. Garzia R. The relationship between visual efficiency problems and learning. In: Scheiman M, Rouse $M$, editors. Optometric management of learning-related vision problems. 1st ed. St. Louis, MO: Mosby, 2006; p. 209-280.

6. Wajuihian SO, Hansraj R. Accommodative anomalies in a sample of black high school students in South Africa. Ophthal Epidemiol. 2016;23:316-323. https:// doi.org/10.3109/09286586.2016.1155715

7. Chen $\mathrm{AH}$, Abidin AHZ. Vergence and accommodation systems in Malay primary school children. J Biomed Sci. 2002;9:9-15.

8. Palomo-Alvarez C, Puell MC. Binocular function in school children with reading difficulties. Graefes Arch Clin Exp Ophthalmol. 2009;248(6):885-892. https://doi. org/10.1007/s00417-009-1251-y

9. Shin SH, Park SC, Park CM. Relationship between accommodative and vergence dysfunctions and academic achievement for primary school children. Ophthal Physiol Opt. 2009;29:615-624. https://doi.org/10.1111/j.1475-1313.2009.00684.x

10. Marran LF, De Land PN, Nguyen, AL. Accommodative insufficiency is the primary source of symptoms in children diagnosed with convergence insufficiency. Optom Vis Sci. 2006;83:281-289.

11. Borsting E, Rouse MW, Deland PN, et al. Association of symptoms and convergence and accommodative insufficiency in school-age children. Optometry. 2003;74:25-34.

12. Davis AL, Harvey EM, Twelker JD, Miller JM, Leonard-Green T, Campus I. Convergence insufficiency, accommodative insufficiency, visual symptoms and Convergence insufficiency, accommodative insufficiency, visual symptoms and
astigmatism in Tohono O'odham students. J Ophthalmol. 2016;2016:7 p. https:// doi.org/10.1155/2016/6963976

13. Jang UJ, Park IJ. Prevalence of general binocular dysfunctions among rura schoolchildren in South Korea. Taiwan J Ophthalmol. 2015;5:177-181. https:// doi.org/10.1016/j.tjo.2015.07.005

14. Hussaindeen JR, Rakshit A, Singh NK, et al. Prevalence of non-strabismic anomalies of binocular vision in Tamil Nadu: report 2 of BAND study. Clin Exp Optom. 2016. https://doi.org/10.1111/cxo.12496

15. Metsing IT, Ferreira JT. Accommodation and vergence status among the $3 \mathrm{rd}$ and 4th graders in a mainstream school in Gauteng. S Afr Optom. 2012;71:22-31. https://doi.org/10.4102/aveh.v71i1.64

16. Moodley VR. Amplitude, facility and accuracy of accommodation in a primary school population. S Afr Optom. 2008;67:147-154. https://doi.org/10.4102/aveh. v68i4.196

17. Scheiman M, Gallaway $M$, Coulter $R$, et al. Prevalence of vision and ocular disease conditions in a clinical paediatric population. J Am Optom Assoc. 1996;67:193-202.

18. Paniccia SM, Ayala AR. Prevalence of accommodation and non-strabismic binocular anomalies in a Puerto Rican paediatric population. Optom Vis Perf. 2015;3:158-164.

19. Abdi S, Rydberg A. Asthenopia in schoolchildren, orthoptic and ophthalmological findings and treatment. Doc Ophthalmol. 2005;11:65-72. https://doi. org/10.1007/s10633-005-4722-4

20. Abdi S, Lennerstrand G, Pansell T, Rydberg A. Orthoptic findings and asthenopia in a population of Swedish schoolchildren aged 6 to 16 years. Strabismus. 2008;16: 47-55. https://doi.org/10.1080/09273970802020243

21. Ovenseri-Ogbomo GO, Ovigwe PE. Vergence findings and horizontal vergence dysfunction among first year university students in Benin City, Nigeria. J Optom. 2015;9:258-263. https://doi.org/10.1016/j.optom.2016.01.004

22. Atowa UC, Wajuihian SO, Hansraj R. Vergence profile and prevalence of nonstrabismic vergence anomalies among school children in Abia State, Nigeria. Strabismic vergence anomalies among school children in Abia State, Nigeria. Ophthalmic Epide

23. Ovenseri-Ogbomo GO, Oduntan AO. Comparison of measured with calculated amplitude of accommodation in Nigerian children aged six to 16 years. Clin Exp Optom. 2015;101:571-577. https://doi.org/10.1111/cxo.12520

24. Cacho-Martinez P, García-Munoz A, Ruiz-Cantero MT. Do we really know the prevalence of accommodative and nonstrabismic binocular dysfunctions? Optometry. 2010;3:185-197. https://doi.org/10.1016/S1888-4296(10)70028-5

25. Hashemi H, Nabovat P, Khabazkhoob M, Yekta A, Emamian MH, Fotouhi A. Does Hofstetter's equation predict the real amplitude of accommodation in children? Clin Exp Optom. 2017;101:123-128. https://doi.org/10.1111/cxo.12550

26. Dwyer $P$, Wick B. The influence of correction upon disorders of vergence and accommodation. Optom VisSci. 1995;72:224-232. https://doi.org/10.1097/00006324199504000-00002 